Research Article

\title{
Plasticity Improvement of Ball-Spun Magnesium Alloy Tube Based on Stress Triaxiality
}

\author{
Chunjiang Zhao $\mathbb{D}^{1,2}$ Feitao Zhang, ${ }^{1}$ Jie Xiong, ${ }^{3}$ Zhengyi Jiang $\mathbb{D}^{1,2}$ Xiaorong Yang, ${ }^{1,2}$ \\ and Hailong Cui ${ }^{2,4}$ \\ ${ }^{1}$ School of Mechanical Engineering, Coordinative Innovation Center of Taiyuan Heavy Machinery Equipment, \\ Taiyuan University of Science and Technology, Taiyuan 030024, China \\ ${ }^{2}$ The School of Mechanical, Materials and Mechatronic Engineering, University of Wollongong, Wollongong, \\ NSW 2522, Australia \\ ${ }^{3}$ Sichuan Aerospace Special Power Research Institute, Chengdu 610100, China \\ ${ }^{4}$ Institute of Machinery Manufacturing Technology, China Academy of Engineering Physics, Mianyang 621000, China
}

Correspondence should be addressed to Zhengyi Jiang; jiang@uow.edu.au

Received 8 December 2017; Accepted 13 February 2018; Published 16 May 2018

Academic Editor: Pavel Lejcek

Copyright (c) 2018 Chunjiang Zhao et al. This is an open access article distributed under the Creative Commons Attribution License, which permits unrestricted use, distribution, and reproduction in any medium, provided the original work is properly cited.

The effects of thickness reduction, feed ratio, and ball diameter, and their coupling effects, on the average relative stress triaxiality during spinning are discussed via simulation results. The relationships among the parameters and the average value of relative stress triaxiality (AVRST) are fitted with multiple nonlinear functions to calculate the optimal process parameters. According to the trend of stress triaxiality, the corresponding process parameters are calculated for the minimum average value of relative stress triaxiality (AVRST). Room temperature experiments performed on an AZ31 magnesium alloy thin-walled tube with the optimal parameters reveal an improvement of cracking of the tube surface. The study reveals changes in the minimum AVRST and aids in selecting the process parameters to improve plastic performance.

\section{Introduction}

The ball-spinning process (Figure 1) employs a support ring, conical ring, screw tube, and numerous balls that collectively constitute the ball-spinning mold. The ball-spinning mold is present on the outer wall of the workpiece. The mold and the workpiece rotate relative to each other, and the mold moves along the axis of the workpiece to produce the axial feed. Then, the workpiece placed outside the mandrel comes into contact with the balls, and the workpiece is compressed to produce plastic deformation. The main parameters for the ball-spinning process are shown in Figure 2, where $R$ is the ball radius, $\Delta t$ is the thickness reduction, $f$ is the feed ratio, and $\alpha$ is the spinning angle.

Rotarescu [1] performed a theoretical derivation and finite-element simulation to establish the relationship between the parameters for ball spinning. Abd-Eltwab et al. [2] studied the effects of processing variables pertaining to ball spinning on the forming load and the quality of the formed sleeves and determined the optimum values of these variables. Li et al. [3] obtained a formula for calculating the ballspinning pressure under the assumption of a plane strain state. Zhang et al. [4] analyzed the folding defects formed by ball spinning at the bottom of the inner grooves of copper tubes according to the results of finite-element analysis. Jiang et al. [5, 6] simulated the ball spinning of a nickeltitanium shape memory alloy tube by the rigid-viscoplastic finite-element method and investigated the interface compatibility of the composite tube of copper and aluminum during ball spinning. In [7], the finite-element method was used to simulate the thin-walled tube ball spinning, and the reasonable process parameters were obtained. Kuss and Buchmayr $[8,9]$ carried out a finite-element simulation and an experiment on the surface cracking phenomenon, which affects the spinning of the workpiece. Jiang et al. $[10,11]$ simulated multipass backward ball spinning and carried out 


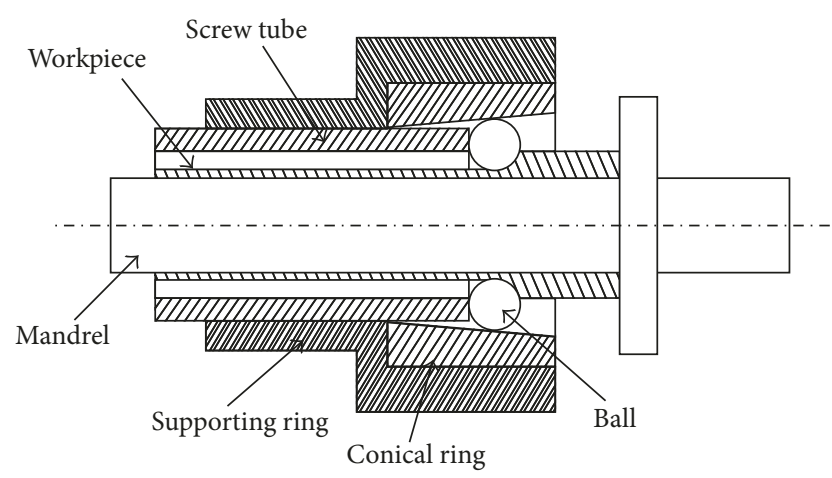

FIGURE 1: Schematic of ball spinning.

a study on the influence of the ball size on deformability of thin-walled tubular part with longitudinal inner ribs.

As mentioned above, previous research on the ballspinning process parameters mostly considered the influence of single-process parameters on the spinning tube, without taking into account the coupling effects of various parameters. As a result, when a process parameter changes, the remaining process parameters cannot be correspondingly adjusted.

\section{Theoretical Basis and Related Hypotheses}

Because of the close-packed hexagonal structure of the metal atom, the magnesium alloy shows poor plasticity and can be easily broken during spinning. Therefore, it is important to select appropriate process parameters to improve the plasticforming ability and thus ensure surface quality.

Internal factors such as deformation temperature, deformation speed, and deformation methods as well as other external factors affect the deformation behavior of magnesium alloys. At present, a large number of studies on the mechanical properties of magnesium alloys are gradually transferred from normal temperature and quasi-static conditions to different temperatures and different strain rates, including fracture strength and fracture ductility [12].

Rod parameter, soft coefficient, and stress triaxiality are the commonly used stress state parameters for studying the deformation and fracture of a metal. From multidirectional tension to multidirectional compression, the stress triaxiality and different stress states show a significant monotonic change; hence, it is imperative to describe the stress state of the material.

The research results show that ductile fracture caused by plastic deformation is affected by parameters such as strain rate and temperature as well as the stress triaxiality $[13,14]$. With an increase in stress triaxiality, the equivalent elastic modulus and equivalent yield stress of a magnesium alloy increase, but its fracture strain gradually decreases [15]. At present, a single stress or strain fracture criterion cannot explain the failure fracture behavior under the complex stress state of a magnesium alloy material. Considering the relationship between the stress triaxiality and the fracture strain as the core of the fracture criterion can help explain

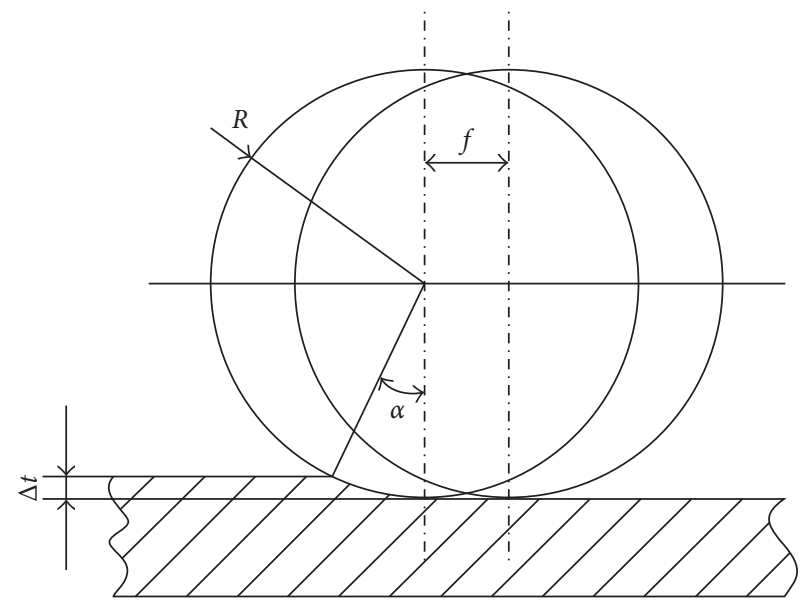

FIgURE 2: Process parameters for ball spinning.

the magnesium alloy failure behavior in different stress states.

The stress triaxiality $\sigma^{*}$ force is given by

$$
\begin{aligned}
\sigma^{*} & =\frac{\sigma_{m}}{\sigma}, \\
\sigma_{m} & =\frac{\sigma_{1}+\sigma_{2}+\sigma_{3}}{3}, \\
\sigma & =\sqrt{\frac{1}{2}\left[\left(\sigma_{1}-\sigma_{2}\right)^{2}+\left(\sigma_{2}-\sigma_{3}\right)^{2}+\left(\sigma_{3}-\sigma_{1}\right)^{2}\right]},
\end{aligned}
$$

where $\sigma_{m}$ is the spherical stress; $\sigma_{1}, \sigma_{2}$, and $\sigma_{3}$ are maximum, intermediate, and minimum principal stresses, respectively; and $\sigma$ is the von Mises equivalent stress.

Generally, the smaller the $\sigma^{*}$ value, the larger is the plastic deformation limit of the material and the better is the plastic-forming ability. El-Magd and Abouridouane [16] studied magnesium alloys and found that, under dynamic loading conditions $\left(\dot{\varepsilon}>10^{-3}\right)$, there was an increase in deformation when the strain rate increased.

From the aspect of cracking of the material surface, the fracture failure of the metal is related to the strain rate and temperature in addition to the stress triaxiality. The most widely accepted and used fracture failure criterion is the Johnson-Cook fracture failure model, which is expressed as follows [17]:

$$
\varepsilon_{f}=\left[D_{1}+D_{2} \exp \left(D_{3} \sigma^{*}\right)\right]\left(1+D_{4} \ln \dot{\varepsilon}\right)\left(1+D_{5} T^{*}\right),
$$

where $\varepsilon_{\mathrm{f}}$ is the fracture strain; $\sigma^{*}$ is the stress triaxiality; $\sigma_{\mathrm{e}}$ is the Mises equivalent stress; $D_{1}, D_{2}, D_{3}, D_{4}$, and $D_{5}$ are the material constants; $\dot{\varepsilon}$ is the strain rate; and $T^{*}$ is a temperature parameter.

According to the literature [17], in formula (2), stress triaxiality is the most important factor affecting the fracture strain; when the hydrostatic pressure increases, the fracture strain decreases rapidly. The fracture strain mainly depends on the hydrostatic pressure state and is less dependent on the strain rate and temperature. 
Thus, stress triaxiality is the decisive factor for the fracture strain of a given material at medium and low strain rates. Although stress triaxiality and equivalent fracture strain can be calculated based on tested data, the material failure strain is not the same as the equivalent fracture strain. Hence, the actual relationship between equivalent strain and stress triaxiality cannot be determined experimentally. For this reason, a numerical simulation must be performed to obtain the accurate stress triaxiality of the specimen.

This study analyzes the change rule for the average value of relative strain triaxiality in the deformation influence zone during the ball spinning of an AZ31 magnesium alloy thinwalled tube. A method for selecting the process parameters based on the stress triaxiality is presented.

Ball spinning is a complex stress-strain process, and the material stress-strain curve changes with the stress state; hence, calculation of the real stress triaxiality is very difficult. Based on the above analysis, the finite-element calculation in this paper has been carried out with the following conservative processing: the strain rate is in the medium-low range and has little effect on the fracture strain; the simulation and experiment are carried out at room temperature, so the effect of temperature on the fracture strain is neglected; a bilinear model of the stress-strain relationship of the material is used in the finite-element model.

Thus, the stress triaxiality value at each point is not the true stress triaxiality but a relative representation of the stress triaxiality. The main purpose is to explore the change in stress triaxiality with different parameters and to provide a qualitative reference for the selection of process parameters toward a small stress triaxiality.

\section{Finite-Element Simulation of Ball Spinning}

3.1. Model Establishment. In this study, the commercial finite-element software ABAQUS is used to simulate the spinning process. The model is simplified accordingly. The support ring, screw tube, and conical ring are ignored, and ball movement is directly defined. The ball, thrust ring, and mandrel are defined as analytical rigid bodies, and only the tube is defined as the elastoplastic body. The eight-node linear hexahedral element C3D8R is used, and the plastic deformation region is remeshed. As the local deformation is large, an enhanced hourglass control is set up. The finiteelement model is shown in Figure 3.

To compare the effects of different process parameters on the stress state of the workpiece (a thin-walled tube), multiple simulations must be conducted. Based on the above discussion, the elastic modulus and yield stress of the workpiece-magnesium alloy tube are given in a simple bilinear model [18] in Table 1. The material properties and process parameters of the tube are shown in Table 1.

3.2. Boundary Condition Settings. In order to maximize the fit of the actual spinning conditions, the boundary conditions for the simulation process are set as follows:

(1) During spinning, the ball rotates in a three-dimensional manner. Hence, the simulation limits its three directions

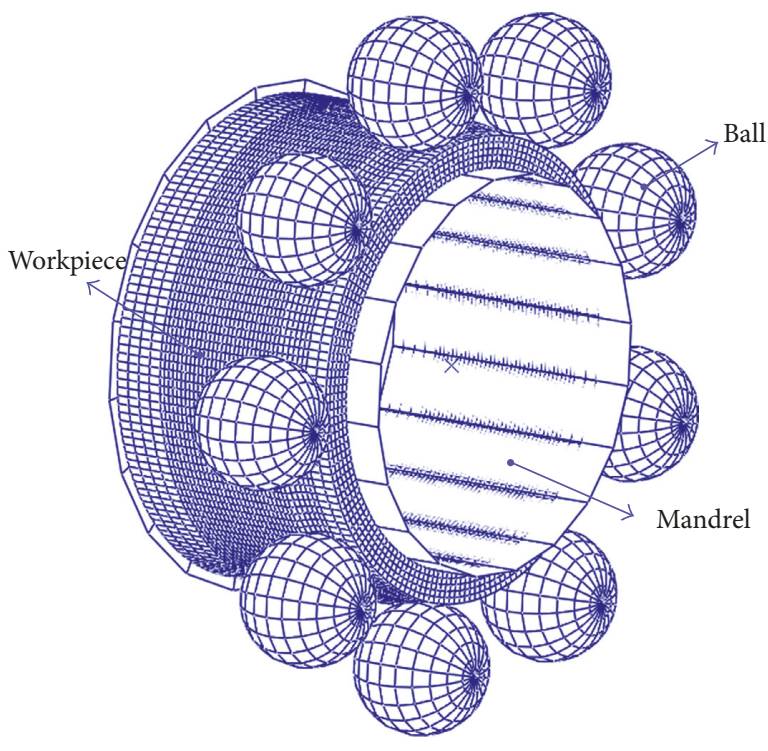

FIgURE 3: Finite-element model.

of translational freedom to retain the rotation freedom.

(2) The tube is in frictional contact with the mandrel and thrust ring at a friction coefficient of 0.08 . The contact between the ball and the magnesium alloy material with lubrication corresponds to a friction coefficient of 0.1 .

(3) The mandrel is fed axially with the workpiece, and the remaining directions of freedom are restricted.

3.3. Data Extraction from Simulation Results. In ball spinning, besides the metal extrusion by the ball just below the ball, the nearby area is also affected. Thus, this study considers the contact area between the ball and tube and the surrounding vicinity as a single ball-deformation-affected area (Figure 4).

The average value of relative stress triaxiality (AVRST) in the affected zone is taken as the basis for the selection of process parameters, which is mainly in the following considerations:

First, the ball and the workpiece are theoretically in the point contact state, so the actual deformation-affected area is very small. The location of the extreme value of stress triaxiality is usually not the position of the maximum position of the stress, and the AVRST can weaken the influence of fluctuations in the extreme value of stress triaxiality of an isolated unit.

Second, the balls are circumferentially distributed along the circumference of the workpiece, and the contact and noncontact states of the ball are continuously repeated at the same point on the workpiece. This repeated state is contained in the deformation-affected zone.

Therefore, it is more reasonable to use the change in the AVRST in the deformation-affected zone to investigate the plastic-forming ability of the deformation zone of the workpiece. 
TABle 1: Properties and process parameters of the blank tube.

\begin{tabular}{|c|c|c|c|c|c|c|c|c|}
\hline Tube material & $\begin{array}{c}\text { Elastic modulus } \\
(\mathrm{MPa})\end{array}$ & $\begin{array}{l}\text { Poisson's } \\
\text { ratio }\end{array}$ & $\begin{array}{l}\text { Yield stress } \\
\left(\sigma_{s}\right)\end{array}$ & $\begin{array}{c}\text { Outside diameter } \\
\text { of tube }(\mathrm{mm})\end{array}$ & $\begin{array}{c}\text { Tube-wall } \\
\text { thickness }(\mathrm{mm})\end{array}$ & $R(\mathrm{~mm})$ & $\Delta t(\mathrm{~mm})$ & $f(\mathrm{~mm} / \mathrm{r})$ \\
\hline \multirow{5}{*}{$\begin{array}{l}\text { Magnesium } \\
\text { alloy (AZ31B) }\end{array}$} & \multirow{5}{*}{44800} & \multirow{5}{*}{0.31} & \multirow{5}{*}{180} & \multirow{5}{*}{ 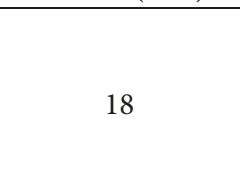 } & \multirow{5}{*}{1.5} & 2.5 & 0.1 & 0.1 \\
\hline & & & & & & 3 & 0.2 & 0.15 \\
\hline & & & & & & 3.5 & 0.3 & 0.2 \\
\hline & & & & & & 4 & 0.4 & 0.25 \\
\hline & & & & & & 4.5 & 0.5 & 0.3 \\
\hline
\end{tabular}

Along the circumferential direction of the workpiece shell, the tension zone between two balls appears at intervals, immediately below the ball; eight units are taken from each side in the ball feeding direction to constitute the deformationaffected zone.

The stress triaxiality value of each element in the set is extracted, as shown in Table 2.

As mentioned above, the stress triaxial values are relative, but its change can be derived from multiple sets of process parameters; this can qualitatively guide the selection of the process parameters in favor of plasticity improvement.

\section{Results of Finite-Element Calculation}

The three main process parameters-ball diameter, thickness reduction, and feed ratio-affect the stress state of the workpiece during spinning, and the coupling effects between these parameters are also significant. Therefore, the relationships between one of these parameters and the other two parameters are studied.

The AVRST in the deformation-affected zone under different parameter configurations for each group in Table 3 is plotted as a graph. Cloud diagrams of relative stress triaxiality by the finite-element method, corresponding to each group of process parameters, are extracted. The areas in which the relative stress triaxiality is greater than zero are set in white color for significant distinction, as shown in Figures 5-10, for each graph and cloud diagram.

\section{Discussion}

According to the calculated data, the relative stress triaxiality for different ball diameters, amounts of thinning, and feed ratios is analyzed and discussed as follows.

5.1. Effect of Ball Diameter. As seen in Figure 5, as the ball diameter gradually increases, the AVRST in the deformationaffected zone decreases first and then increases. This observation indicates that excessively small or excessively large ball diameters are not suitable for the plastic deformation capacity.

As can be seen from curves 1 and 3 in Figure 5, the minimum AVRST in the deformation-affected zone appears at $R=3 \mathrm{~mm}$, while the spinning angle is

$$
\alpha=\arccos \frac{R-\Delta t}{R}=\arccos \frac{3-0.2}{3}=21^{\circ} .
$$

Curve 2 shows the minimum value when $R=4.5 \mathrm{~mm}$, and the corresponding spinning angle is

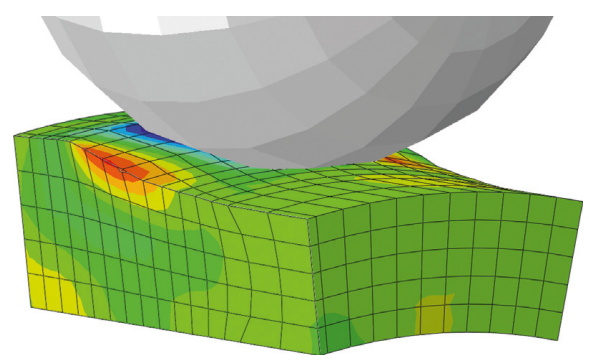

Figure 4: Deformation-affected area.

$$
\alpha=\arccos \frac{R-\Delta t}{R}=\arccos \frac{4.5-0.3}{4.5}=21.04^{\circ} .
$$

This angle is consistent with the best spinning angle obtained by the production practice mentioned in the literature [19].

From the contrasting trend for curves 1 and 3 in Figure 6, it is seen that with an increase in the ball diameter, the difference in AVRST increases. The corresponding AVRST plotted on curves 1 and 3 increases rapidly, but curve 2 is relatively flat. This indicates that when a larger ball diameter is used, a smaller feed ratio and larger thickness reduction should be adopted.

To analyze the distribution of stress triaxiality in Figure 6 , a nodal flow vector diagram of the section of the contact area between the ball and the workpiece is extracted, as shown in Figure 11.

Notably, the contact area of the ball is squeezed during spinning. In this case, the relative stress triaxiality is small. During the movement of the ball along the circumference of the workpiece, the material flow velocity is lower on the adjacent front and rear areas of the ball than in the ball contact area. Thus, the frontal pressure and rear tensile stress states are formed.

Moreover, a band-like tensile stress region is generated on the workpiece surface in the direction of about $45^{\circ}$ because of the large shearing stress.

When the ball diameter is small, the deformation area is also small. In this case, the relative stress triaxiality in most areas is small and negative. With an increase in ball diameter, the area of plastic deformation and the area in which the relative stress triaxiality is positive increase, but the relative stress triaxiality pole value decreases from 5.16 to 4.71 .

Moreover, when the ball diameter is $R=4 \mathrm{~mm}$, the minimum value of relative stress triaxiality is larger than that at $R=3 \mathrm{~mm}$, and this minimum value generally appears immediately below the ball. This indicates that as the ball diameter 
TABLe 2: Average stress triaxial value for different process parameters.

\begin{tabular}{|c|c|c|c|c|c|c|c|c|c|c|c|c|c|c|}
\hline No. & $R$ & $\Delta t$ & $f$ & TRIAX & No. & $R$ & $\Delta t$ & $f$ & TRIAX & No. & $R$ & $\Delta t$ & $f$ & TRIAX \\
\hline 1 & 2.5 & 0.2 & 0.2 & -0.7413 & 13 & 2.5 & 0.3 & 0.1 & -0.1733 & 25 & 4.5 & 0.3 & 0.2 & -0.8001 \\
\hline 2 & 3.5 & 0.2 & 0.2 & -0.9252 & 14 & 2.5 & 0.3 & 0.15 & -0.4531 & 26 & 4.5 & 0.4 & 0.2 & -0.6585 \\
\hline 3 & 4 & 0.2 & 0.2 & -0.8034 & 15 & 2.5 & 0.3 & 0.25 & -0.4681 & 27 & 4.5 & 0.5 & 0.2 & -0.6274 \\
\hline 4 & 4.5 & 0.2 & 0.2 & -0.7574 & 16 & 2.5 & 0.3 & 0.3 & -0.2836 & 28 & 3 & 0.1 & 0.2 & -0.6487 \\
\hline 5 & 2.5 & 0.2 & 0.3 & -0.6020 & 17 & 2.5 & 0.2 & 0.1 & -0.4014 & 29 & 3 & 0.2 & 0.2 & -1.0312 \\
\hline 6 & 3.5 & 0.2 & 0.3 & -0.7252 & 18 & 2.5 & 0.2 & 0.15 & -0.6340 & 30 & 3 & 0.4 & 0.2 & -0.5260 \\
\hline 7 & 4 & 0.2 & 0.3 & -0.5834 & 19 & 2.5 & 0.2 & 0.25 & -0.7329 & 31 & 3 & 0.5 & 0.2 & -0.4594 \\
\hline 8 & 4.5 & 0.2 & 0.3 & -0.5074 & 20 & 3 & 0.2 & 0.1 & -0.5552 & 32 & 3 & 0.1 & 0.3 & -0.5487 \\
\hline 9 & 2.5 & 0.3 & 0.2 & -0.5699 & 21 & 3 & 0.2 & 0.15 & -0.8883 & 33 & 3 & 0.3 & 0.3 & -0.5886 \\
\hline 10 & 3 & 0.3 & 0.2 & -0.8416 & 22 & 3 & 0.2 & 0.25 & -0.9686 & 34 & 3 & 0.4 & 0.3 & -0.3063 \\
\hline 11 & 3.5 & 0.3 & 0.2 & -0.7552 & 23 & 3 & 0.2 & 0.3 & -0.8766 & 35 & 3 & 0.5 & 0.3 & -0.2050 \\
\hline 12 & 4 & 0.3 & 0.2 & -0.7634 & 24 & 4.5 & 0.1 & 0.2 & -0.4416 & & & & & \\
\hline
\end{tabular}

TABle 3: Process parameters.

\begin{tabular}{|c|c|c|c|}
\hline Process parameters & \multicolumn{3}{|c|}{ Different ball diameters $R(\mathrm{~mm})$} \\
\hline$\Delta t(\mathrm{~mm})$ & 0.2 & 0.2 & 0.3 \\
\hline $\mathrm{f} / \mathrm{mm} / \mathrm{r}$ & 0.2 & 0.3 & 0.2 \\
\hline$R(\mathrm{~mm})$ & \multicolumn{3}{|c|}{$2.5,3.0,3.5,4.0,4.5$} \\
\hline Process parameters & \multicolumn{3}{|c|}{ Different amounts of thinning $\Delta t(\mathrm{~mm})$} \\
\hline $\mathrm{f} / \mathrm{mm} / \mathrm{r}$ & 0.2 & 0.3 & 0.2 \\
\hline$R(\mathrm{~mm})$ & 3 & 3 & 4.5 \\
\hline$\Delta t(\mathrm{~mm})$ & \multicolumn{3}{|c|}{$0.1,0.2,0.3,0.4,0.5$} \\
\hline Process parameters & \multicolumn{3}{|c|}{ Different feed ratios $f(\mathrm{~mm})$} \\
\hline$R(\mathrm{~mm})$ & 2.5 & 2.5 & 3 \\
\hline$\Delta t(\mathrm{~mm})$ & 0.2 & 0.3 & 0.2 \\
\hline $\mathrm{f} / \mathrm{mm} / \mathrm{r}$ & & $0.1,0.15,0.2$, & \\
\hline
\end{tabular}

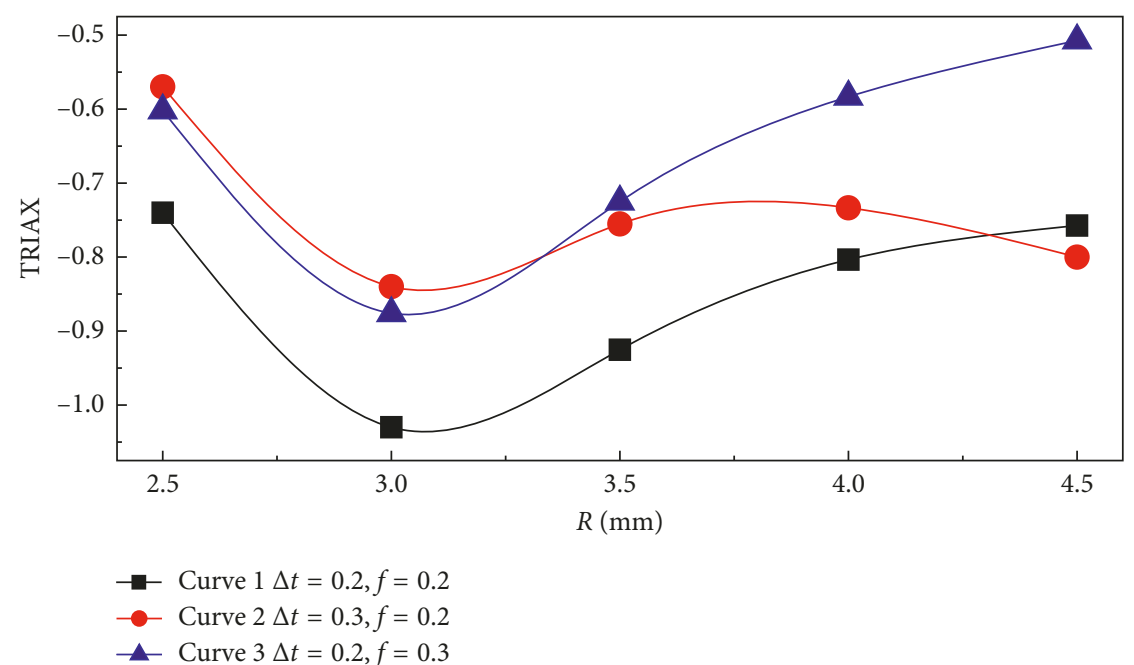

FIgURE 5: Graph of change in AVRST with ball diameter.

increases, the plastic limit of the material decreases, and particularly, the extent of the thickness reduction is diminished. Moreover, when the ball radius increases, the extremum of relative stress triaxiality in the tension region increases, so excessively small ball diameters are highly undesirable.

5.2. Effect of Thickness Reduction. In Figure 7, the AVRST decreases first and then increases with increasing thickness reduction. This observation indicates that excessively high or low thickness reductions are not conducive for ductileforming ability. From the three curves in Figure 7, when the ball diameter is $R=3 \mathrm{~mm}$, the thickness reduction corresponding to the minimum AVRST is 0.2. When the ball diameter is $R=4.5 \mathrm{~mm}$, the thickness reduction corresponding to the minimum AVRST is 0.3 . These two values satisfy the following relation:

$$
\Delta t=R\left(1-\cos 21^{\circ}\right) .
$$




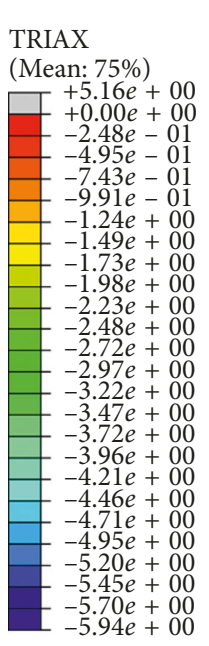

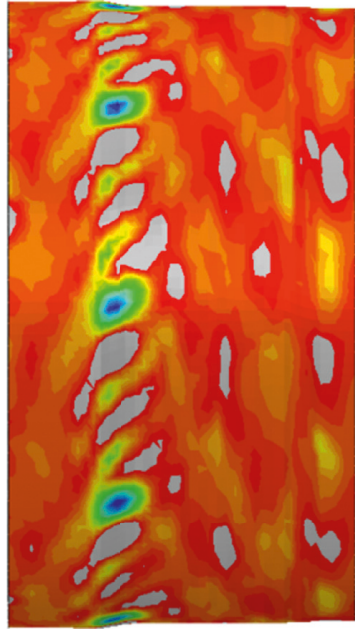

(a)
TRIAX

(Mean: 75\%)

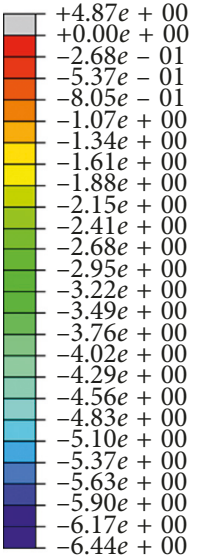

$-6.44 e+00$

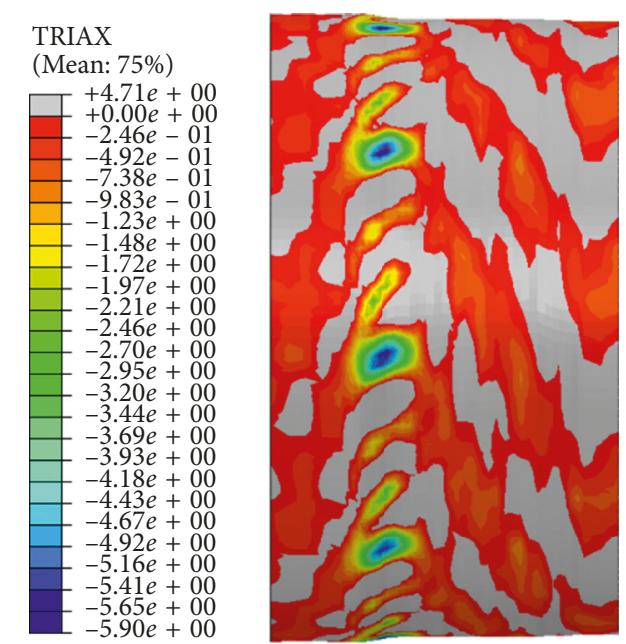

(c)

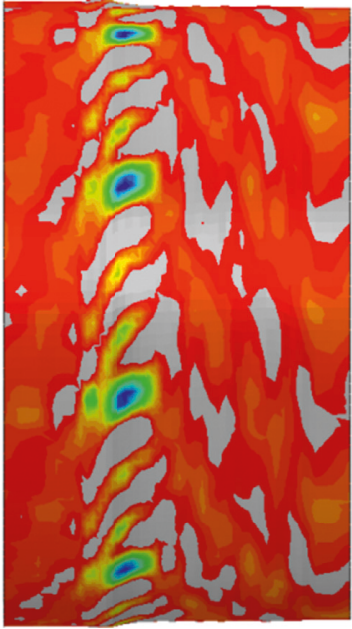

(b) 


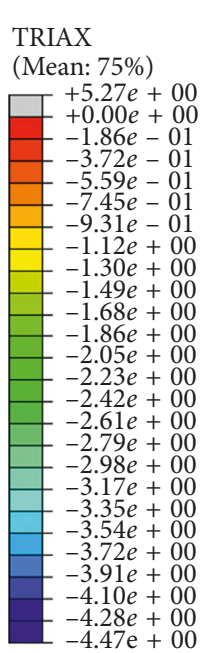

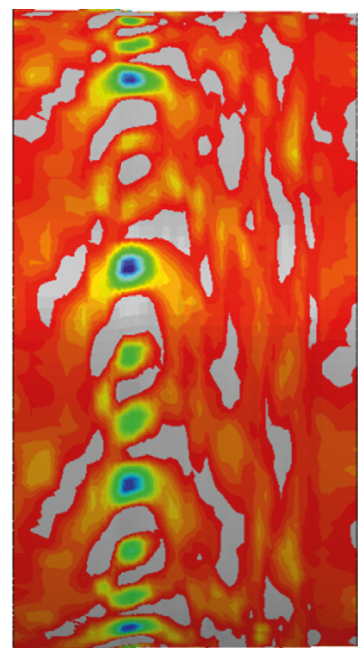

(a)

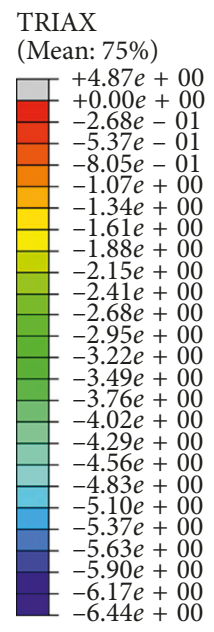

$-6.44 e+00$

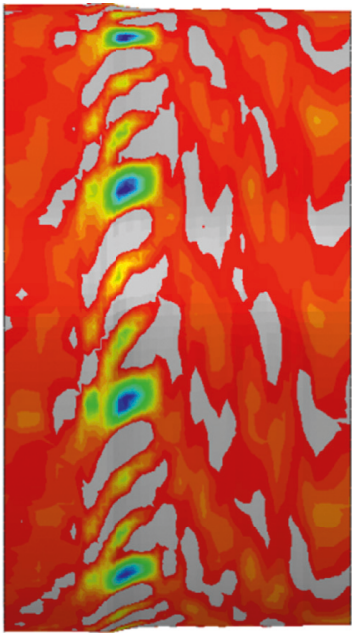

(b)
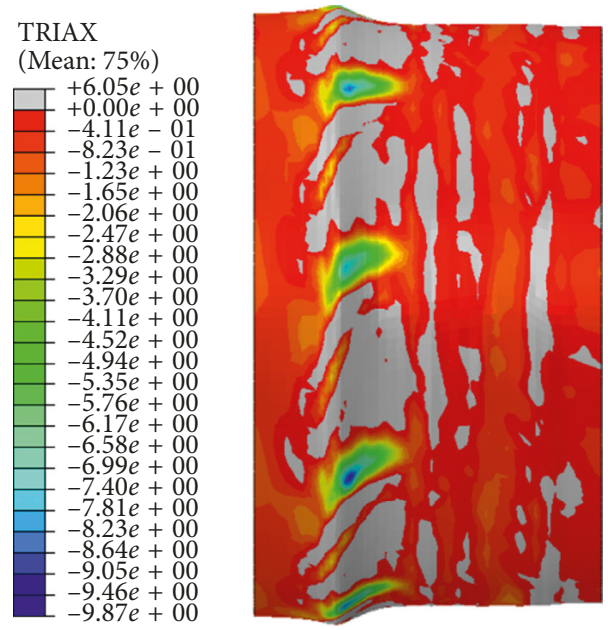

(c)

FiguRE 8: Cloud diagram of relative stress triaxiality for different amounts of thinning. (a) $R=3 \mathrm{~mm}, f=0.2 \mathrm{~mm} / \mathrm{r}$, and $\Delta t=0.1 \mathrm{~mm}$. (b) $R=3 \mathrm{~mm}, f=0.2 \mathrm{~mm} / \mathrm{r}$, and $\Delta t=0.2 \mathrm{~mm}$. (c) $R=3 \mathrm{~mm}, f=0.2 \mathrm{~mm} / \mathrm{r}$, and $\Delta t=0.4 \mathrm{~mm}$.

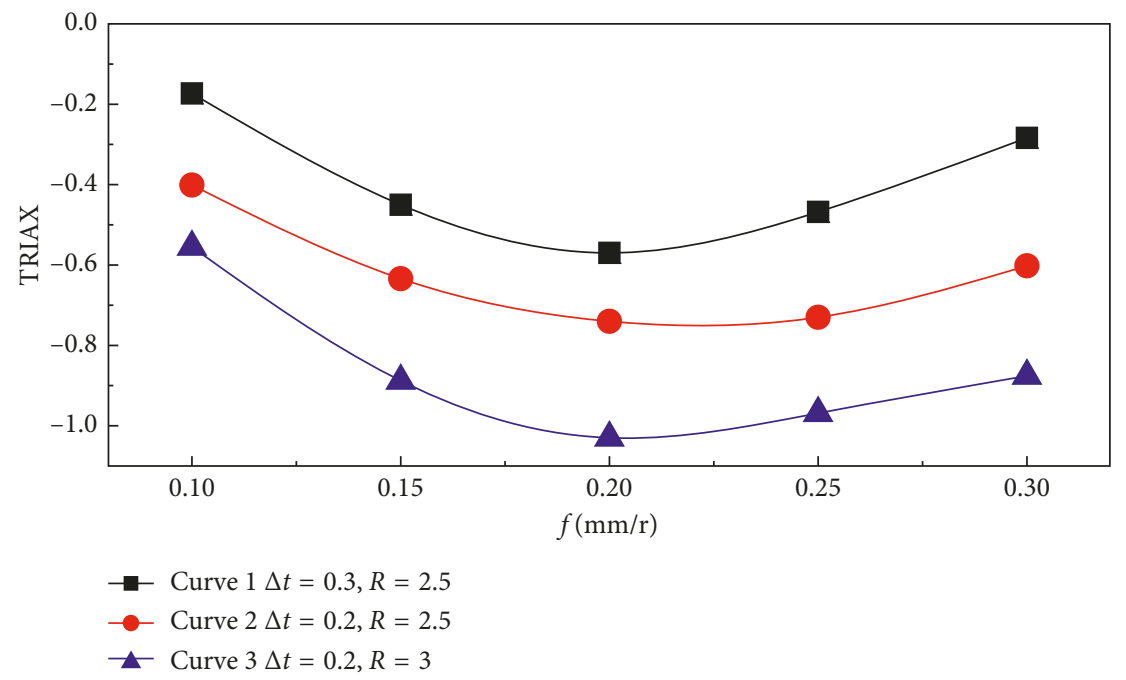

FIGURE 9: Graph of change in AVRST with feed ratio. 


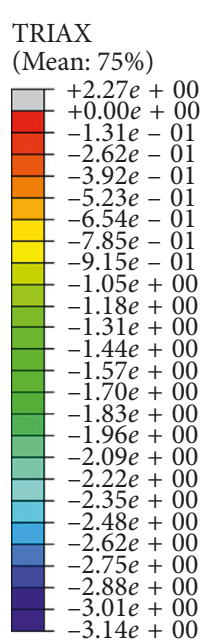

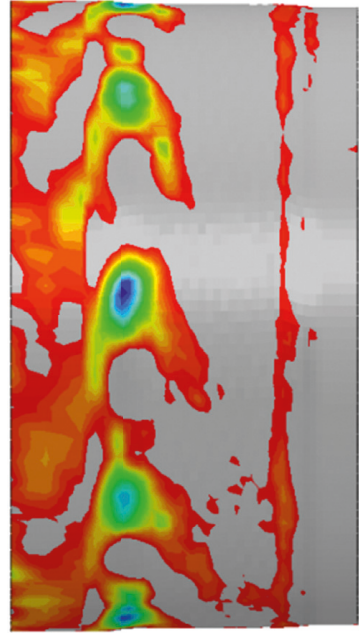

(a)
TRIAX (Mean: 75\%)

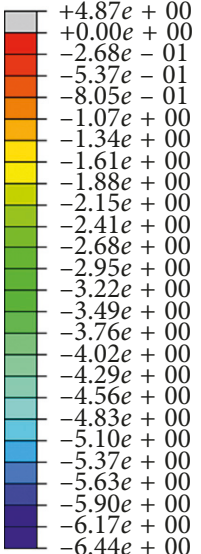

$-6.44 e+00$

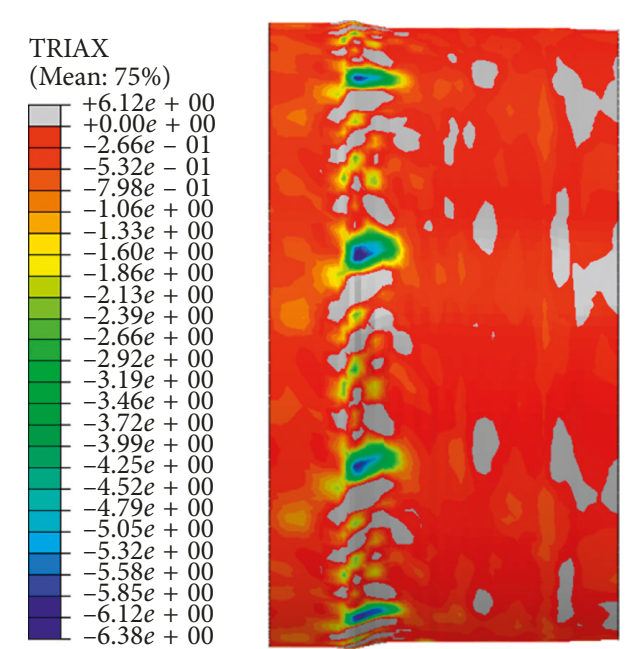

(c)

FIGURE 10: Cloud diagram of relative stress triaxiality under different feed ratios. (a) $R=3 \mathrm{~mm}, f=0.1 \mathrm{~mm} / \mathrm{r}$, and $\Delta t=0.2 \mathrm{~mm}$. (b) $R=3 \mathrm{~mm}$, $f=0.2 \mathrm{~mm} / \mathrm{r}$, and $\Delta t=0.2 \mathrm{~mm}$. (c) $R=3 \mathrm{~mm}, f=0.3 \mathrm{~mm} / \mathrm{r}$, and $\Delta t=0.2 \mathrm{~mm}$.

This correspondence implies that the optimum spinning angle is always about $21^{\circ}$, which is consistent with the analysis results in Section 5.1.

When the thickness reduction exceeds the optimum value, the growth of curves 2 and 3 is faster than that of curve 1 . The smaller the ball diameter, the more sensitive is the change in the AVRST to the thickness reduction. Since there are intersections between curve 1 and curves 2 and 3 , the influence of ball diameter on the AVRST exceeds the influence of feed ratio when the thickness reduction exceeds that corresponding to the intersection. Therefore, when the thickness reduction is large, the ball diameter match should be first considered. As the thickness reduction increases, curve 2 grows more rapidly than curve 3; that is, as the thickness reduction increases, a larger feed ratio leads to a poor stress state. Therefore, when the ball diameter is the same, the feed ratio should be reduced accordingly when the thickness reduction increases.

Figure 8 shows that the minimum value of relative stress triaxiality decreases with an increase in the thickness reduction,

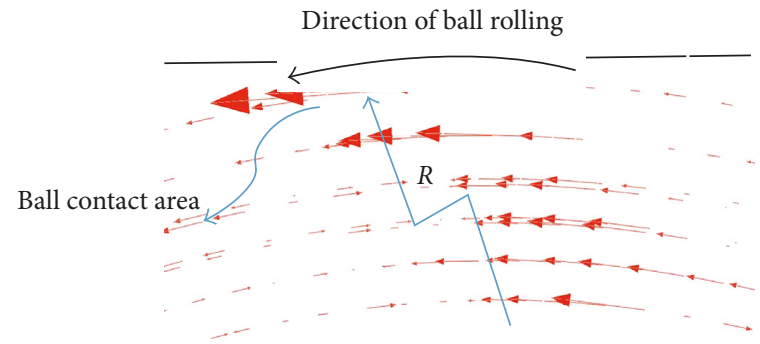

FIGURE 11: Flow vector diagram of nodes of cross section at the contact area center.

and that its maximum value decreases first and then decreases with an increase in the thickness reduction. With an increase in the thickness reduction, the area similar to an inclined strip, where the relative stress triaxiality is greater than 0 decreases and the inclination angle progressively decreases; however, the tensioned area between the two balls increases gradually. 
TABle 4: Fitting function coefficient.

\begin{tabular}{cccccccc}
\hline$a_{1}$ & $a_{2}$ & $a_{3}$ & $a_{4}$ & $a_{5}$ & $a_{6}$ & $a_{7}$ & $a_{8}$ \\
$-2.84 E-01$ & $-5.49 E+01$ & $-4.49 E+01$ & $-7.78 E-02$ & $3.64 E-01$ & $-1.41 E+01$ & $-3.92 E-01$ & $-4.06 E+00$ \\
$a_{9}$ & $b_{1}$ & $b_{2}$ & $b_{3}$ & $c_{1}$ & $c_{2}$ & $c_{3}$ & $d$ \\
$2.42 E+01$ & $3.07 E+00$ & $6.02 E+01$ & $6.15 E+01$ & $-1.10 E+01$ & $-1.64 E+01$ & $-1.95 E+01$ & $1.52 E+01$ \\
\hline
\end{tabular}

TABLE 5: Fitness determination parameters.

\begin{tabular}{lcccc}
\hline RMSE & SSE & $R$ & $R^{2}$ & DC \\
\hline 0.032591414 & 0.037177010 & 0.987666548 & 0.975485211 & 0.975485211 \\
\hline
\end{tabular}

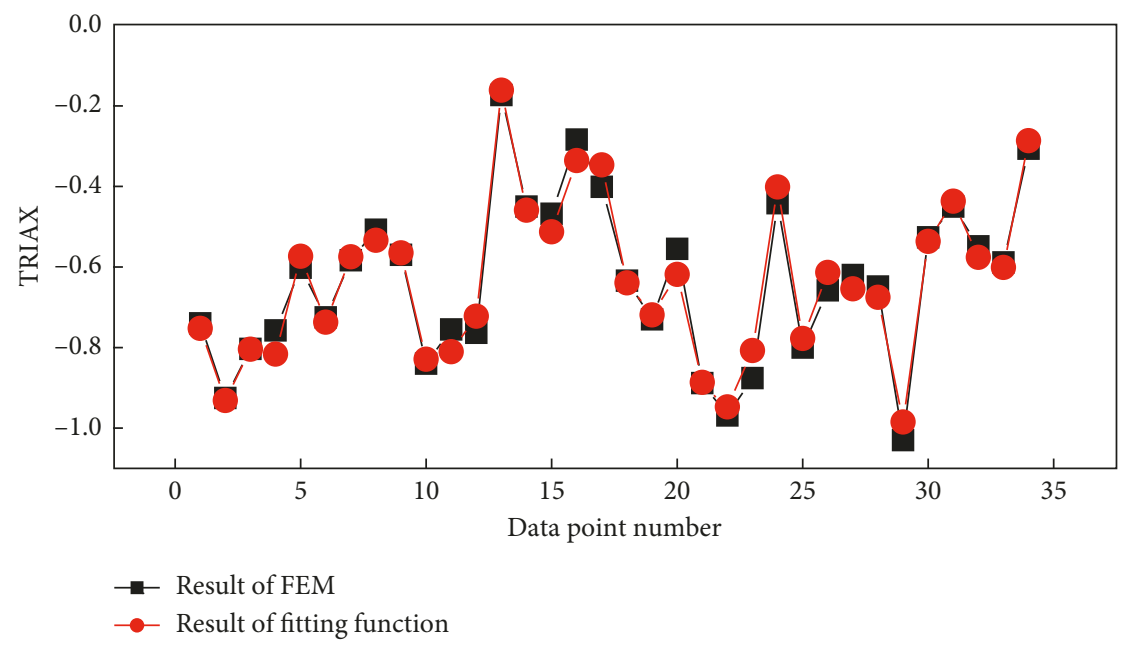

Figure 12: Comparison of the measured values of the average stress triaxiality and the calculated values of the fitting function.

In addition, with an increase in the thickness reduction, the area of the unspun section of the workpiece in which the relative stress triaxiality is greater than 0 shows a decreasing trend. This is because as the thickness reduction increases, the radial spinning force component increases faster than the axial force and tangential force component [20]; therefore, a larger thickness reduction is advantageous for reducing circumferential torsional failure and axial pressure buckling.

5.3. Effect of Feed Ratio. As seen in the three curves in Figure 9, the AVRST first decreases and then increases with increasing feed ratio. This plot indicates that an excessively large or small feed ratio is not conducive for improving the plastic-forming ability of the tube, and all the feed ratios corresponding to the minimum AVRST is about 0.2. By comparing curve 1 and curve 2, it can be seen that, at a larger thickness reduction, we must use a smaller feed ratio to achieve better stress states. By comparing curve 2 and curve 3 , it can be seen that when the ball diameter increases, the feed ratio used should also be high for a smaller AVRST.

Figure 10 shows that when the feed ratio is small, the AVRST of the deformation-affected zone is large. The area mainly distributed in the spinned region, where the relative stress triaxiality is greater than 0 is large, but the maximum relative stress triaxiality is 2.27 , which is smaller than that for the other cases, indicating that it is difficult to break the material under these conditions.

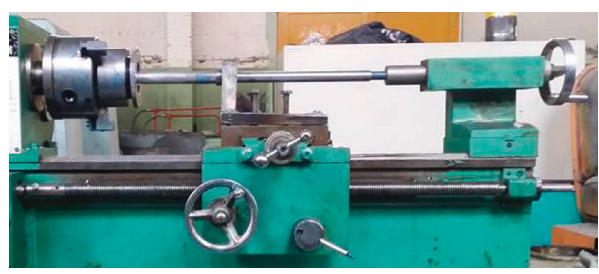

FIGURE 13: Experimental equipment.

\section{Multivariate Nonlinear Function Fitting}

From the above analysis, the trend of AVRST with the change of process parameters is obtained, so the nonlinear function is fitted according to the existing calculation data in the following text. So that when a process parameter changes, it is easy to match the remaining process parameters.

According to the simulation results, the three-variable cubic polynomial is selected as fitting function. During the fitting analysis using the standard ternary cubic polynomial model, it is found that a significant collinearity relationship exists among the four items of $R \Delta t f, R \Delta t, R f$, and $\Delta t f$ in the polynomial. However, when these four items are applied into the fitting function model, the model becomes distorted, and the fitting results are not estimated. Therefore, these four items on the standard ternary cubic polynomial model are eliminated, and the final fitting function model is attained consequently as follows: 


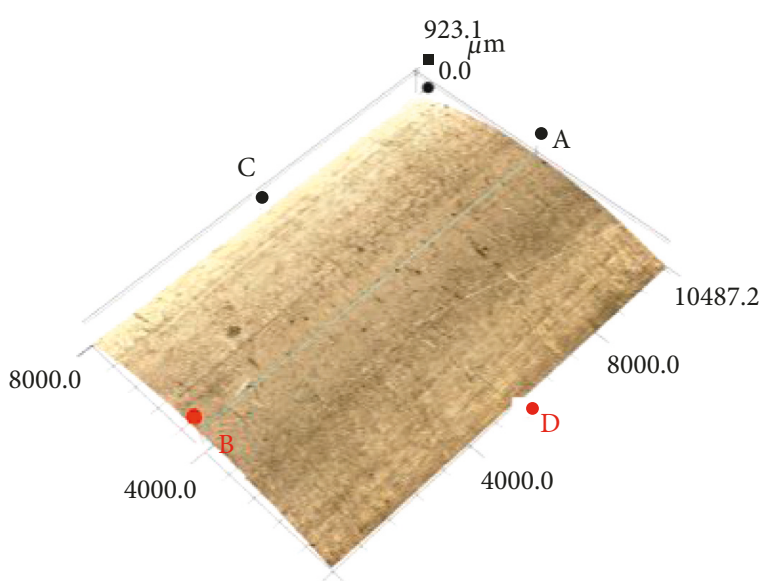

$0.0 \mu \mathrm{m} \quad 0.0 \mu \mathrm{m}$

(a)

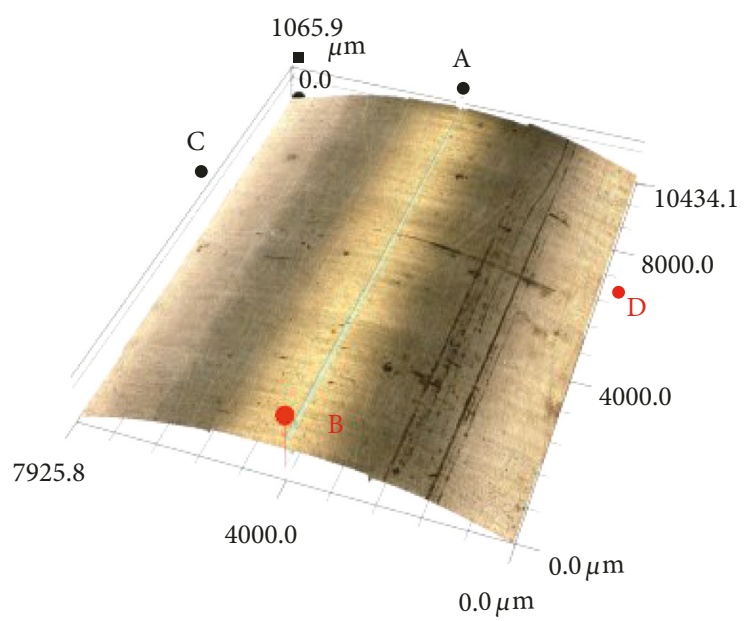

(b)

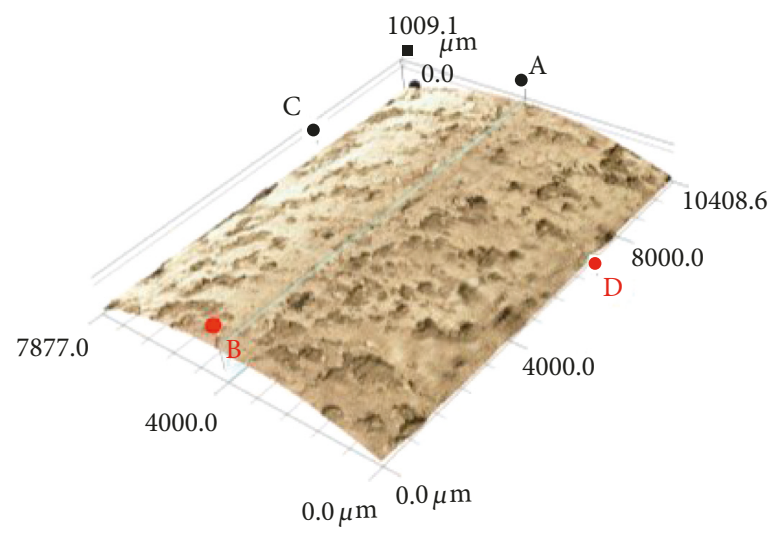

(c)

FiguRE 14: Tube after spinning at different thickness reductions. (a) $R=3 \mathrm{~mm}, f=0.2 \mathrm{~mm} / \mathrm{r}$, and $\Delta t=0.1 \mathrm{~mm}$. (b) $R=3 \mathrm{~mm}, f=0.2 \mathrm{~mm} / \mathrm{r}$, and $\Delta t=0.2 \mathrm{~mm}$. (c) $R=3 \mathrm{~mm}, f=0.2 \mathrm{~mm} / \mathrm{r}$, and $\Delta t=0.4 \mathrm{~mm}$.

$$
\begin{aligned}
R_{d}= & a_{1} R^{3}+a_{2} \Delta t^{3}+a_{3} f^{3}+a_{4} R^{2} \Delta t+a_{5} R^{2} f \\
& +a_{6} \Delta t^{2} f+a_{7} R \Delta t^{2}+a_{8} R f^{2}+a_{9} \Delta t f^{2}+b_{1} R^{2} \\
& +b_{2} \Delta t^{2}+b_{3} f^{2}+c_{1} R+c_{2} \Delta t+c_{3} f+d .
\end{aligned}
$$

The data in Table 2 are used, and the results are shown in Table 4.

The fitting degree of the fitting function is also considered, and the determination parameters are shown in Table 5.

The plot in Figure 12 compares the compatibility between the results of FEM and fitting function.

In Figure 12, the compatibility between the measured value of the AVRST and the calculated value of the fitting function is high with no point of complete deviation, so the fitting function model given in this paper is reliable.

At the given range of ball diameter of $2.5 \mathrm{~mm} \leq R \leq 4.5 \mathrm{~mm}$, thickness reduction of $0.1 \mathrm{~mm} \leq \Delta t \leq 0.5 \mathrm{~mm}$, and the feed ratio of $0.1 \mathrm{~mm} / \mathrm{r} \leq f \leq 0.3 \mathrm{~mm} / \mathrm{r}$, the optimal process parameters that correspond to the minimum AVRST are obtained as follows: $R=3.01, \Delta t=0.205$, and $f=0.208$.

\section{Experimental Verification}

The material used in the experiment is a magnesium alloy AZ31B extruded tube. The horizontal spinning machine used in the experiment is shown in Figure 13, and it can achieve feed ratios of $0.1,0.2$, and $0.3 \mathrm{~mm} / \mathrm{r}$.

However, the inner diameter of the conical ring is limited, so the ball diameter cannot be changed arbitrarily to adjust the range of thickness reductions. Therefore, the experimental ball diameter is fixed $R=3.0 \mathrm{~mm}$, and the experiment only explores the changes of thickness reduction and feed ratio. In line with the previous finite-element analysis, the number of balls used in the experiment is 9, and the spinning mold is filled with grease.

To clearly observe the tube surface after spinning for comparative analysis, the spinned tube surface is examined by an ultradepth microscope.

Spinning experiments are carried out for different thickness reductions and feed ratios. The experimental results are shown in Figures 14 and 15.

Figure 14(a) shows that the pipe surface is smoother and shows minor cracks. In Figure 14(b), the surface finish is the highest, and there are no obvious cracks except for the 


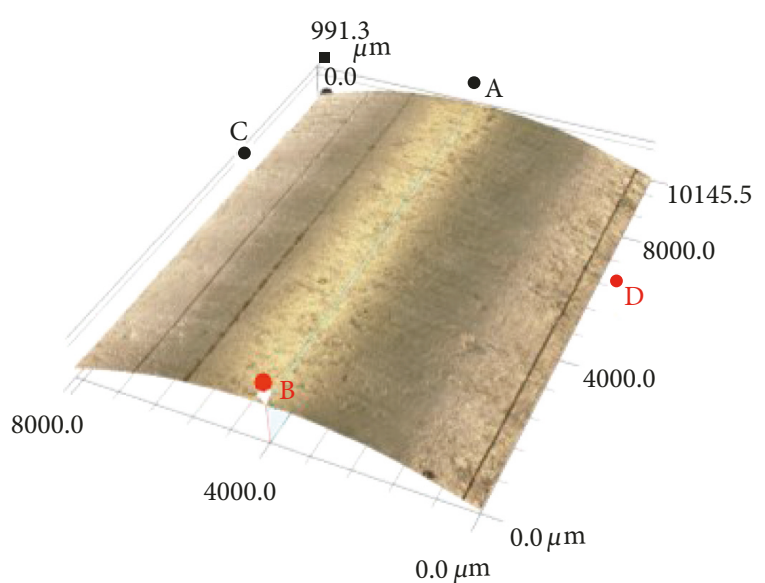

(a)

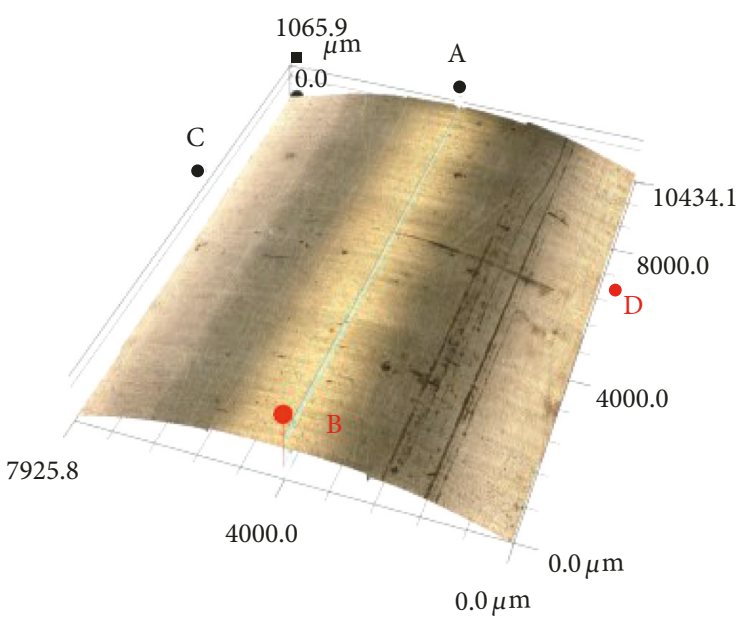

(b)

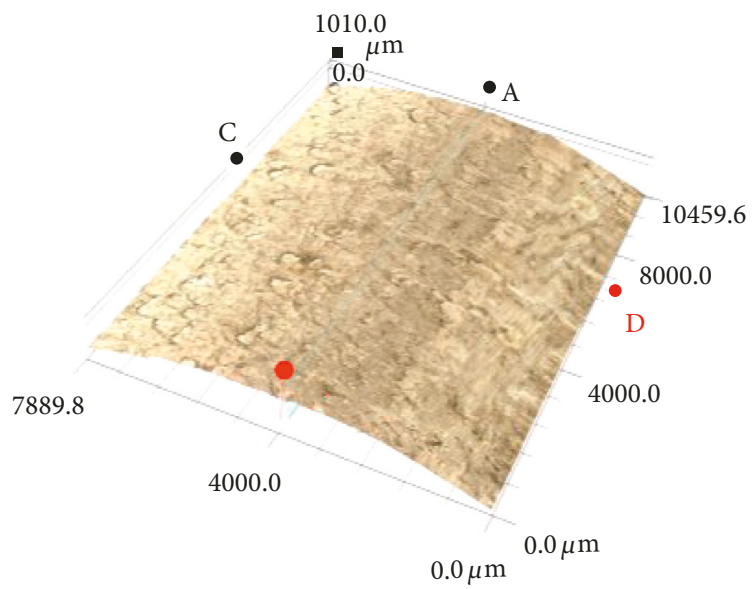

(c)

Figure 15: Tube after spinning under different feed ratios. (a) $R=3 \mathrm{~mm}, f=0.1 \mathrm{~mm} / \mathrm{r}$, and $\Delta t=0.2 \mathrm{~mm}$. (b) $R=3 \mathrm{~mm}, f=0.2 \mathrm{~mm} / \mathrm{r}$, and $\Delta t=0.2 \mathrm{~mm}$. (c) $R=3 \mathrm{~mm}, f=0.3 \mathrm{~mm} / \mathrm{r}$, and $\Delta t=0.2 \mathrm{~mm}$.

original scratches on the surface of the tube. The tube surface in Figure 14(c) is seriously damaged, and deep cracks are visible along the tube circumference.

In Figure 15(a), the pipe surface shows no obvious cracks and debris but displays a poor and dim finish. Figure 15(b) is the same as Figure 14(b). In Figure 15(c), the surface shows visible cracks and a rolled skin, and the micrographs reveal a stack of layers on the surface.

It can be seen from the experimental results that the quality of the spinned tube is closely related to the AVRST, and the failure of the tube after spinning is consistent with the simulation results. It is thus demonstrated that the method for using the AVRST to characterize the plasticforming ability of the material is feasible.

\section{Conclusion}

In this paper, the influence of the process parameters on the stress state of the spinning deformation zone during ball spinning is described by finite-element simulation. The relationship among the three parameters-ball diameter, feed ratio, and thickness reduction - and the average stress triaxiality are discussed. Finally, spinning experiments are carried out, and the following conclusions are drawn.

The AVRST for the ball-spinning deformation first decreases and then increases with changes in the three main process parameters. Excessively large or small values of the ball diameter, feed ratio, and thickness reduction are not conducive for improving the plastic-forming ability of the tube. When a large thickness reduction is used, a large ball diameter can improve the stress state. When the feed ratio is large, the ball diameter is reduced, and the stress state in the deformation-affected zone is improved; increasing the ball diameter and reducing the feed ratio is beneficial for improving the plastic-forming capacity of the tube. The fitting formula used in this paper can predict the AVRST of the deformation-affected zone of the workpiece accurately within a certain range of process parameters.

\section{Conflicts of Interest}

The authors declare that there are no conflicts of interest. 


\section{Acknowledgments}

The authors would like to thank the National Natural Science Foundation of China (no. 51375325), the Shanxi Coal Based Low Carbon Joint Fund (U1610118 and U1510131), the Shanxi Provincial Special Fund for Coordinative Innovation Center of Taiyuan Heavy Machinery Equipment, and the Fund for Shanxi "1331 Project" Key Subjects Construction for their support to this research.

\section{References}

[1] M. I. Rotarescu, "A theoretical analysis of tube spinning using balls," Journal of Materials Processing Technology, vol. 54, no. 1-4, pp. 224-229, 1995.

[2] A. A. Abd-Eltwab, S. Z. El-Abden, K. I. E. Ahmed, M. N. ElSheikh, and R. K. Abdel-Magied, "An investigation into forming internally-spline sleeves by ball spinning," International Journal of Mechanical Sciences, vol. 134, pp. 399-410, 2017.

[3] M. Li, S. Zhang, D. Kang et al., "Ball diameter selection in ball spinning process," Materials Science and Technology, vol. 13, no. 6, pp. 594-597, 2005.

[4] G. Zhang, S. Zhang, B. Li, and H. Zhang, "Analysis on folding defects of inner grooved copper tubes during ball spin forming," Journal of Materials Processing Technology, vol. 184, no. 1-3, pp. 393-400, 2007.

[5] S. Jiang, Y. Q. Zhang, Y. N. Zhao et al., "Finite element simulation of ball spinning of NiTi shape memory alloy tube based on variable temperature field," Transactions of Nonferrous Metals Society of China, vol. 23, no. 3, pp. 781-787, 2013.

[6] S. Jiang, Y. Q. Zhang, Y. Zhao, X. Zhu, D. Sun, and M. Wang, "Investigation of interface compatibility during ball spinning of composite tube of copper and aluminum," International Journal of Advanced Manufacturing Technology, vol. 88, no. 1-4, pp. 683-690, 2017.

[7] F. A. Hua, Y. S. Yang, Y. N. Zhang et al., "Three-dimensional finite element analysis of tube spinning," Journal of Materials Processing Technology, vol. 168, no. 1, pp. 68-74, 2005.

[8] M. Kuss and B. Buchmayr, "Damage minimised ball spinning process design," Journal of Materials Processing Technology, vol. 234, pp. 10-17, 2016.

[9] M. Kuss and B. Buchmayr, "Analytical, numerical and experimental investigations of a ball spinning expansion process," Journal of Materials Processing Technology, vol. 224, pp. 213-221, 2015.

[10] S. Jiang, Z. Ren, C. Li, and K. Xue, "Role of ball size in backward ball spinning of thin-walled tubular part with longitudinal inner ribs," Journal of Materials Processing Technology, vol. 209, no. 4, pp. 2167-2174, 2009.

[11] S. Jiang, Y. Zheng, Z. Ren, and C. Li, "Multi-pass spinning of thin-walled tubular part with longitudinal inner ribs," Transactions of Nonferrous Metals Society of China, vol. 19, no. 1, pp. 215-221, 2009.

[12] N. Gupta, D. Dung, P. Luong, and K. Rohatgi, "A method for intermediate strain rate compression testing and study of compressive failure mechanism of Mg-Al-Zn alloy," Journal of Applied Physics, vol. 109, no. 10, p. 103512, 2011.

[13] C. Lou, X. Zhang, G. Duan et al., "Characteristics of twin lamellar structure in magnesium alloy during room temperature dynamic plastic deformation," Journal of Materials Science and Technology, vol. 30, no. 1, pp. 41-46, 2014.

[14] M. R. Barnett, K. Zohreh, A. G. Beer, and D. Atwell, "Influence of grain size on the compressive deformation of wrought Mg-3Al-1Zn,” Acta Materialia, vol. 52, no. 17, pp. 5093-5103, 2004.

[15] Q. Li, F. Ji, and F. Li, "Relationship between stress state and stress state parameters in plastic deformation," Forging and Stamping Technology, vol. 39, no. 3, pp. 122-126, 2014.

[16] E. El-Magd and M. Abouridouane, "Characterization, modelling and simulation of deformation and fracture behaviour of the light-weight wrought alloys under high strain rate loading," International Journal of Impact Engineering, vol. 32, no. 5, pp. 741-758, 2006.

[17] J. W. Hancock and D. K. Brown, "On the role of strain and stress state in ductile failure," Journal of Mechanics and Physics of Solids, vol. 31, no. 1, pp. 1-24, 1983.

[18] B. Wang, D. Q. Yi, W. Gu, and X. Fang, "Thermal simulation on hot deformation behavior of ZK60 and ZK60 (0.9Y) magnesium alloys," Rare Metal Material and Engineering, vol. 39, no. 1, pp. 106-122, 2010.

[19] D. Kang, M. Li, and Y. Chen, "A study of force and power in ball spinning," Materials Science and Technology, vol. 10, no. 2, pp. 179-182, 2002.

[20] Y. Liu, X. Gao, C. Zhao, and N. Wang, "Research on numerical simulation of ball spinning for thin-wall tube," Chinese Journal of Engineering Design, vol. 22, no. 6, pp. 562-568, 2015. 


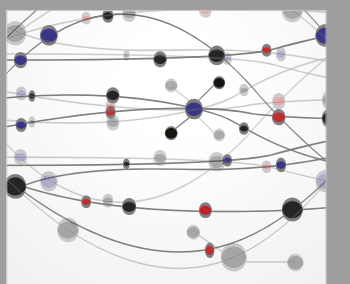

The Scientific World Journal
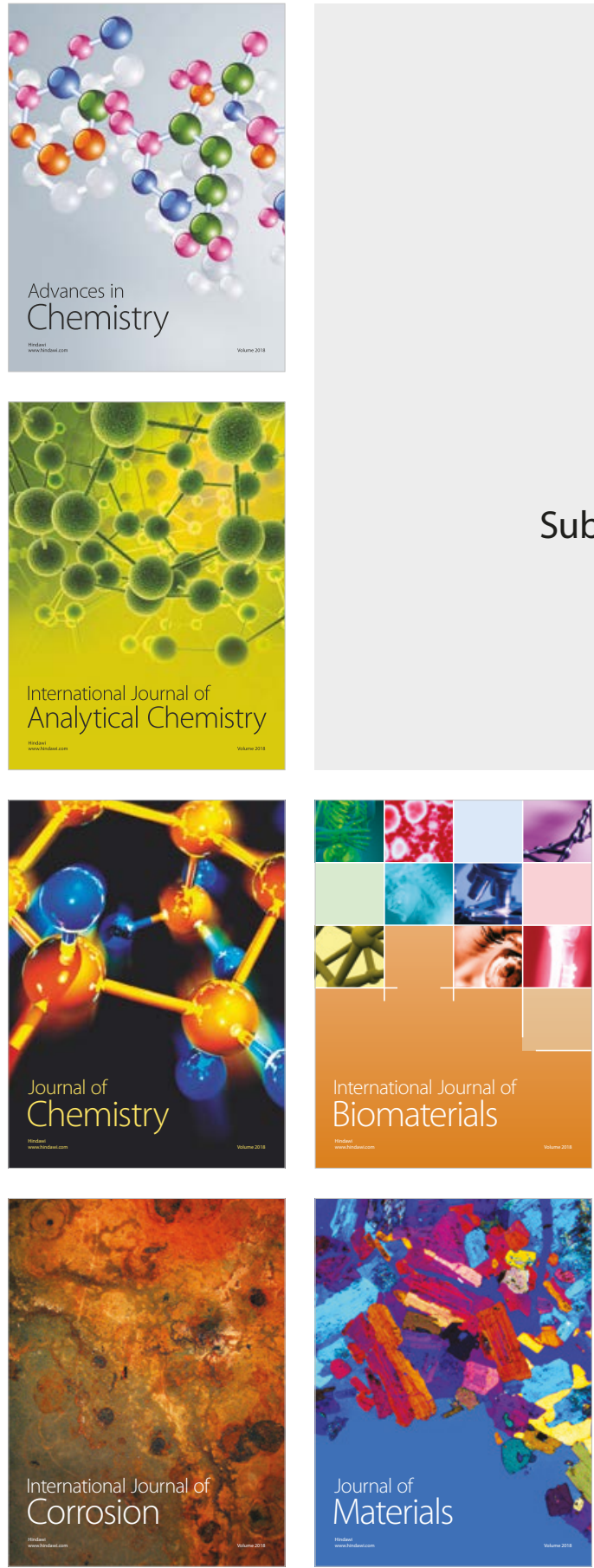

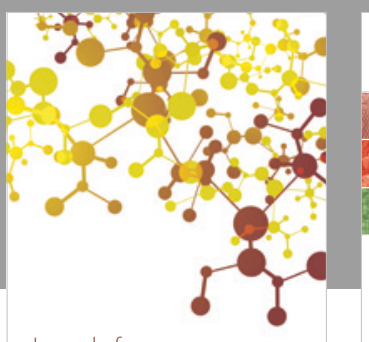

Journal of

Applied Chemistry
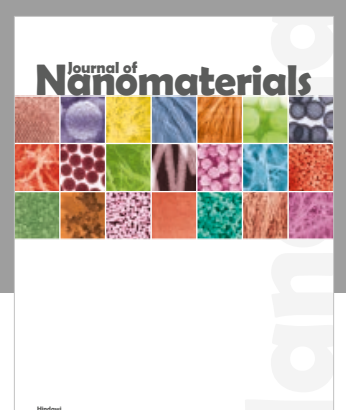

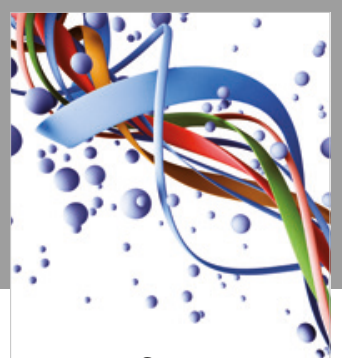

Scientifica

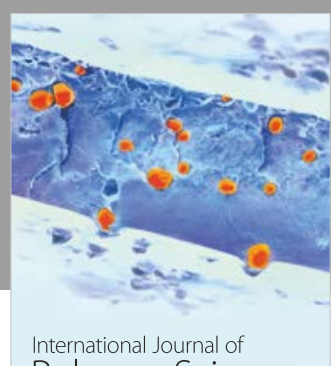

Polymer Science

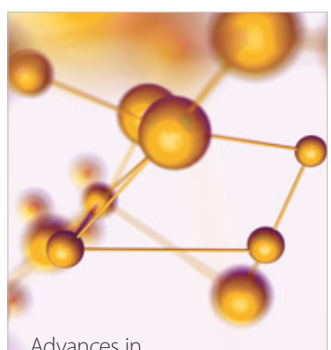

Physical Chemistry
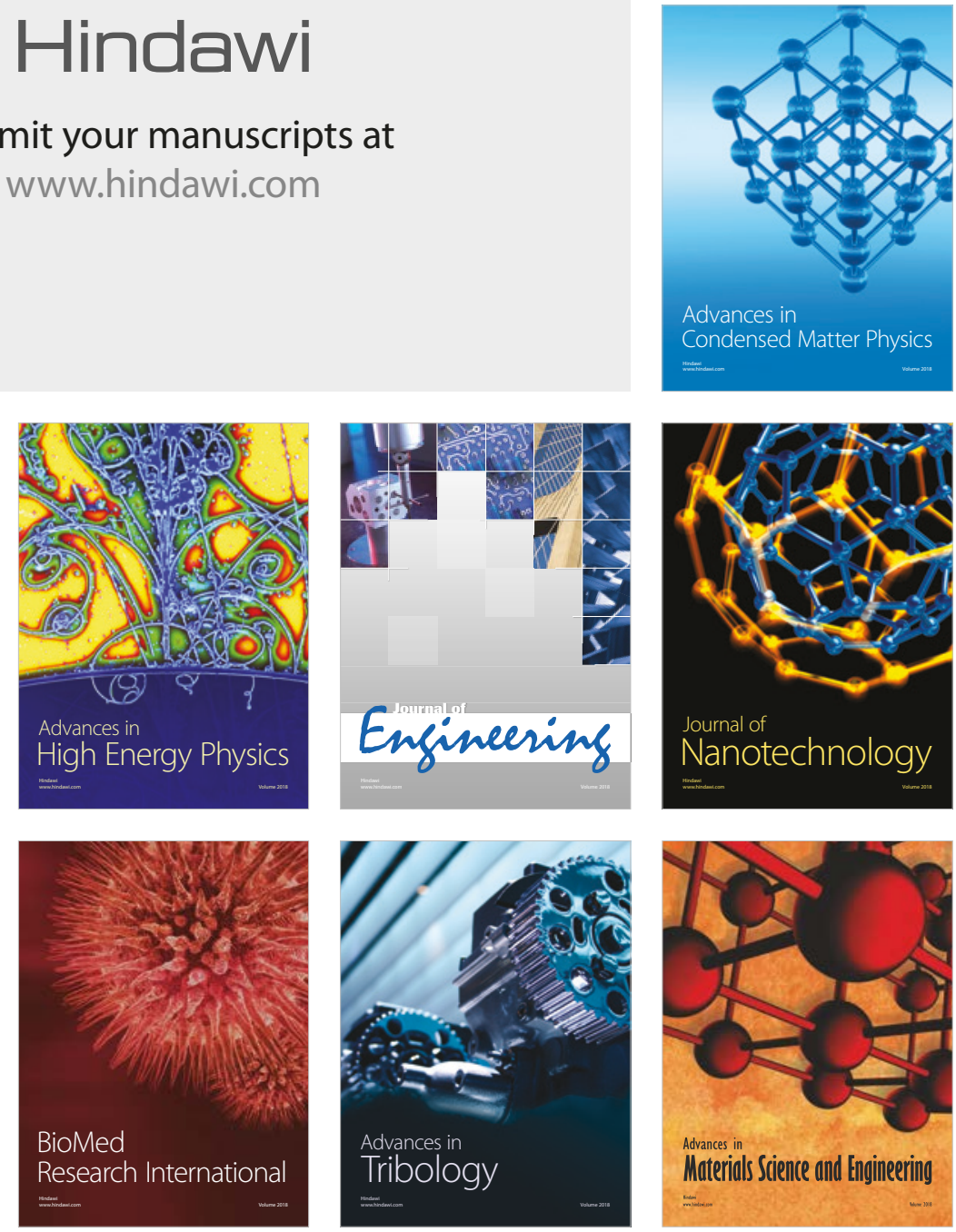